\title{
A Novel Fuzzy-Adaptive Hysteresis Controller Based Three Phase Four Wire-Four Leg Shunt Active Filter for Harmonic and Reactive Power Compensation
}

\author{
Rathika Ponpandi $^{1}$, Devaraj Durairaj ${ }^{2}$ \\ ${ }^{1}$ Electronics and Communication Engineering, Cape Institute of Technology, Levengipuram, \\ Tamilnadu, India \\ ${ }^{2}$ Research and Development, Kalasalingam University, Krishnankoil, Tamilnadu, India \\ E-mail: rathikasakthikumar@yahoo.co.in,deva230@yahoo.com \\ Received August 4, 2011; revised September 5, 2011; accepted September 19, 2011
}

\begin{abstract}
This paper presents a fuzzy logic based three phase four wire four-leg shunt active power filter to suppress harmonic currents. Modified instantaneous $\mathrm{p}-\mathrm{q}$ theory is adopted for calculating the compensating current. Fuzzy-adaptive hysteresis band technique is applied for the current control to derive the switching signals for the voltage source inverter. A fuzzy logic controller is developed to control the voltage of the DC capacitor. Computer simulations are carried out on a sample power system to demonstrate the suitability of the proposed control strategy, for harmonic reduction under three different conditions namely, ideal, unbalance, unbalance and distorted source voltage conditions. The proposed control strategy is found to be effective to reduce the harmonics and compensate reactive power and neutral current and balance load currents under ideal and non-ideal source voltage conditions.
\end{abstract}

Keywords: Harmonics, Shunt Active Power Filter (APF), Harmonics, Hysteresis Band, Fuzzy Logic Control, P-Q Theory

\section{Introduction}

Active filters are widely employed in distribution system to reduce the harmonics [1]. Various topologies of active filters have been proposed for harmonic mitigation. The shunt active power filter based on Voltage Source Inverter (VSI) structure is an attractive solution to harmonic current problems. The shunt active filter is a Pulse Width Modulated (PWM) voltage source inverter that is connected in parallel with the load. Active filter injects harmonic current into the AC system with the same amplitude but with opposite phase as that of the load. The principal components of the APF are the Voltage Source Inverter (VSI), DC energy storage device, coupling inductance and the associated control circuits. The performance of an active filter depends mainly on the technique used to compute the reference current and the control strategy followed to inject the compensation current into the line.

There are two major approaches that have been proposed in the literature for harmonic detection, namely, frequency domain and time domain methods [2]. The time domain methods require less computation and are widely followed for computing the reference current. The two mostly used time domain methods are synchronous reference (d-q- 0 ) theory [3] and instantaneous real-reactive power $(p-q)$ theory $[4,5]$. Though p-q theory has good transient response time and steady state accuracy [6], it is found to be not suitable for estimating reference current under non-ideal source voltage conditions. Hence modified Instantaneous p-q theory $[7,8]$ is followed in this work for harmonic detection.

There are several control strategies proposed in the literature for current control namely, PI control [2], predictive current control [9], Sliding Mode Control (SMC) [10] and hysteresis control [11]. Among the various current control techniques, hysteresis control is the most commonly used method because of its simplicity in implementation. But, with fixed hysteresis band, the slope of the reference current is unpredictable [12], which leads to increase in switching frequency. Dell Aquila [13] have proposed a hysteresis current controller with fixed switching frequency which results in low current tracking error [14]. But this method gives high value of THD 
with increased amount of neutral current. Kale et al. [15] have proposed an adaptive hysteresis band controller for APF application. The adaptive hysteresis band controller changes the hysteresis bandwidth as a function of reference compensator current variation to optimize switching frequency and Total Harmonic Distortion (THD) of the supply current. But in this method, the source current is found to posses large number of spikes which increases the THD value. This paper proposes an adaptive hysteresis band control, where the hysteresis bandwidth is calculated with the help of a fuzzy logic controller (FLC). In this approach, the source current shaping can be achieved with minimum amount of spikes resulting in reduction in THD and reduction in neutral current to zero.

Another important task in the development of active filter is the maintenance of constant DC voltage across the capacitor connected to the inverter. This is necessary to compensate the energy loss due to conduction and switching power losses associated with the diodes and IGBTs of the inverter in APF, which tend to reduce the value of voltage across the DC capacitor. Generally, PI controller [16] is used to control the DC bus voltage. The PI controller based approach requires precise mathematical model which is difficult to obtain and it fails to perform satisfactorily under parameter variations, nonlinearity, and load disturbances [17]. Also, in this conventional method, the source current shaping is achieved with significant number of spikes. This paper proposes a fuzzy logic based approach for D.C voltage control. With this controller, it is possible to design a control system by adjusting the control surface for different working conditions, so that the controller can follow the reference voltage without any spikes.

An active filter developed using the proposed control strategy is simulated using MATLAB/Simulink and its performance in suppressing the harmonics is demonstrated in a sample power system under unbalanced and distorted source voltage conditions.

\section{Proposed Control Strategy}

The active power filter topology presented in this paper is shown in Figure 1. The power system is configured with four wires. The AC source is connected to a set of non-linear loads. Voltages $V_{a}, V_{b}, V_{c}$ and current $I_{a}, I_{b}, I_{c}$ indicate the phase voltages and currents at the load side respectively. $I_{n}$ is the neutral current of the load side. The Active Power Filter consists of three principal parts, a three phase four leg full bridge voltage source inverter, a DC side capacitor and the coupling inductance $L_{f}$. The capacitor is used to store energy and the inductance is used to smoothen the ripple present in the harmonic current injected by the active power filter. The shunt active filter generates the compensating currents $I_{f a}, I_{f b}, I_{f c}$ to compensate the load currents $I_{a}, I_{b}, I_{c}$ so as to make the current drawn from the source $\left(I_{s a}, I_{s b}, I_{s c}\right)$ as sinusoidal and balanced. The performance of the active filter mainly depends on the technique used to compute the reference current and the control system used to inject the desired compensation current into the line. In this paper, the modified $p-q$ theory is used to determine the current

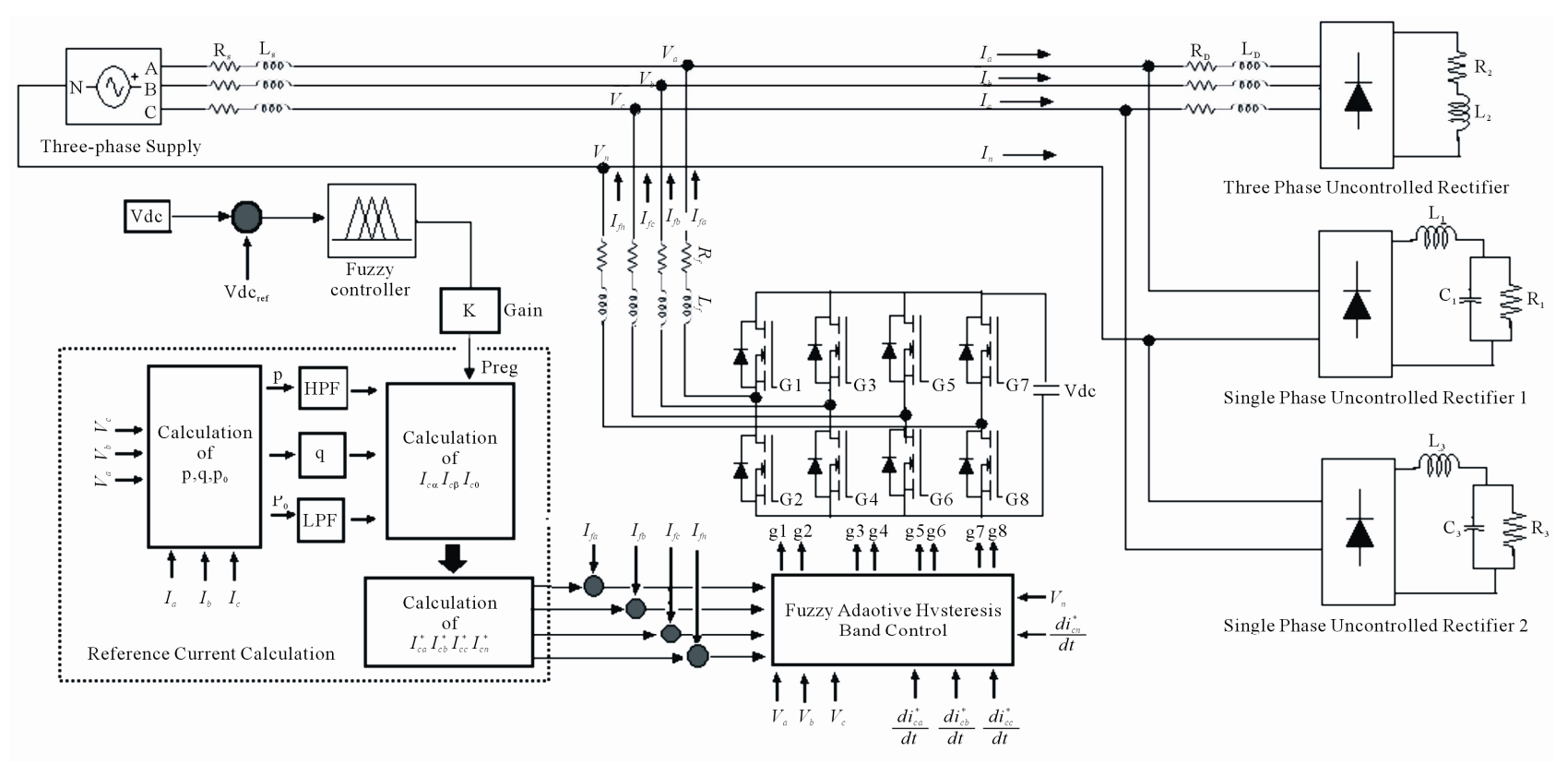

Figure 1. Basic configuration of shunt active filter. 
references $\left(I_{c a}{ }^{*}, I_{c b}{ }^{*}, I_{c c}{ }^{*}\right)$. In Figure 1, the blocks indicated inside the dotted line corresponds to the reference current calculation. A fuzzy logic controller with error (between the capacitor voltage and reference voltage) and change in error as input and real power requirement as output is developed to control $V_{d c}$.

A fuzzy adaptive HBCC is used for generating the required switching signals for the inverter. The source reference current $\frac{\mathrm{d} i_{f a}^{*}}{\mathrm{~d} t}$ and the supply voltage $v_{s}(t)$ are given as input and the hysteresis bandwidth is the output of the fuzzy controller. The details of reference current computation, fuzzy-logic based D.C voltage control and fuzzy adaptive hysteresis band control are presented in the subsequent sections.

\section{Algorithm for Reference Current Calculation}

One of the most important tasks involved in the development of an active filter is the formulation of harmonic detection method. In this work, the modified instantaneous active and reactive power theory (p-q theory) [6] is employed to calculate instantaneously the reference currents. The modified $\mathrm{p}-\mathrm{q}$ algorithm is a combination of $\mathrm{p}-\mathrm{q}$ algorithm and a positive sequence voltage detector algorithm.

In this method the voltages and currents from the three phase four-wire system are first transformed into a three-axis representation $\alpha-\beta-0$, using the following equations:

$$
\begin{aligned}
& {\left[\begin{array}{l}
V_{0} \\
V_{\alpha} \\
V_{\beta}
\end{array}\right]=\sqrt{\frac{2}{3}}\left[\begin{array}{ccc}
1 / \sqrt{2} & 1 / \sqrt{2} & 1 / \sqrt{2} \\
1 & -1 / 2 & -1 / 2 \\
0 & -\sqrt{3} / 2 & -\sqrt{3} / 2
\end{array}\right]\left[\begin{array}{l}
V_{a} \\
V_{b} \\
V_{c}
\end{array}\right]} \\
& {\left[\begin{array}{l}
I_{0} \\
I_{\alpha} \\
I_{\beta}
\end{array}\right]=\sqrt{\frac{2}{3}}\left[\begin{array}{ccc}
1 / \sqrt{2} & 1 / \sqrt{2} & 1 / \sqrt{2} \\
1 & -1 / 2 & -1 / 2 \\
0 & -\sqrt{3} / 2 & -\sqrt{3} / 2
\end{array}\right]\left[\begin{array}{l}
I_{a} \\
I_{b} \\
I_{c}
\end{array}\right]}
\end{aligned}
$$

The power components $p$ and $q$ are related to the $\alpha-\beta$ voltages and currents, and can be written together as given below,

$$
\left[\begin{array}{l}
p \\
q
\end{array}\right]=\left[\begin{array}{cc}
V_{\alpha} & V_{\beta} \\
-V_{\beta} & V_{\alpha}
\end{array}\right]\left[\begin{array}{c}
I_{\alpha} \\
I_{\beta}
\end{array}\right]
$$

The instantaneous zero sequence power is given by,

$$
p_{0}=V_{0} I_{0}
$$

where $p$ is the instantaneous real power and $\mathrm{q}$ is the instantaneous imaginary power and $p_{0}$ is the instantaneous zero-sequence power. The instantaneous real and zero sequence power has in turn a mean value or dc component $\left(\bar{p}, \bar{p}_{0}\right)$ and an oscillating value or ac component $\left(\tilde{p}, \tilde{p}_{0}\right)$.

The objective of the $\mathrm{p}-\mathrm{q}$ theory is to make the source to deliver the constant active power demanded by the load. At the same time the source should not deliver any zero sequence active power. The reference source current in the $\alpha-\beta-0$ frame is therefore,

$$
\left[\begin{array}{c}
i_{c \alpha}^{*} \\
i_{c \beta}^{*}
\end{array}\right]=\left[\begin{array}{cc}
V_{\alpha} & -V_{\beta} \\
V_{\beta} & V_{\beta}
\end{array}\right]\left[\begin{array}{c}
\tilde{p}-\bar{p}_{0} \\
q
\end{array}\right]
$$

Since the zero-sequence current must be compensated, the reference compensation current in the zero coordinate is $I_{0}$ itself:

$$
i_{c 0}=I_{0}
$$

In order to obtain the reference compensation currents in the a-b-c coordinates, the inverse of the transformation given in expression (2) is taken as given below,

$$
\left[\begin{array}{l}
i_{c a}{ }^{*} \\
i_{c b}{ }^{*} \\
i_{c c}{ }^{*}
\end{array}\right]=\left[\begin{array}{ccc}
1 / \sqrt{2} & 1 & 0 \\
1 / \sqrt{2} & 1 / 2 & \sqrt{3} / 2 \\
1 / \sqrt{2} & -1 / 2 & -\sqrt{3} / 2
\end{array}\right]\left[\begin{array}{l}
i_{c 0}{ }^{*} \\
i_{c \alpha}{ }^{*} \\
i_{c \beta}{ }^{*}
\end{array}\right]
$$

The compensation current for neutral is given by

$$
i_{c n}=-\left(i_{c a}^{*}+i_{c b}^{*}+i_{c c}^{*}\right)
$$

In the $\mathrm{p}-\mathrm{q}$ theory presented above, it is assumed that the source voltage is sinusoidal and balanced. If the source voltage is not sinusoidal, this algorithm generates a current with harmonic components [5]. In such a case, the Phase Locked Loop (PLL) can be used to eliminate the harmonic components in the voltage at the point of common coupling.

The block diagram representation of the PLL circuit is given in Figure 2. PLL is used to detect the fundamental positive-sequence component of the voltage at the PCC and hence the influence of other loads on the shunt filter performance can be eliminated. This method is called as modified instantaneous $\mathrm{p}$-q theory which is suitable for balanced, unbalanced and distorted source voltage conditions. This modified $\mathrm{p}-\mathrm{q}$ theory is followed in this work.

\section{Fuzzy Adaptive Hysteresis Current Controller}

Hysteresis current controller derives the switching signals of the inverter power switches (IGBTs). The current controllers of the three phases are designed to operate independently. Each current controller determines the switching signals to its inverter bridge. The switching logic for phase $\mathrm{A}$ is formulated as follows 


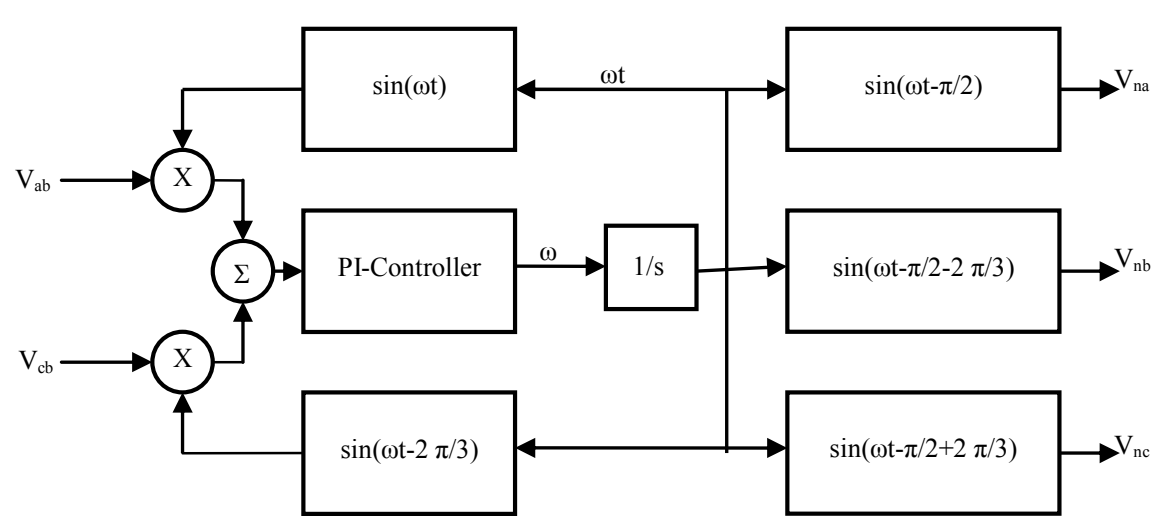

Figure 2. Phase locked loop circuit.

If $i_{f a}<\left(i_{f a}^{*}-H B\right)$ upper switch is OFF and lower switch is ON.

If $i_{f a}<\left(i_{f a}^{*}+H B\right)$ upper switch is ON and lower switch is OFF.

In a similar manner, the switching logic for devices in phase $\mathrm{B}$ and $\mathrm{C}$ are derived.

The switches are controlled asynchronously to ramp the current through the inductor up and down so that it follows the reference. The current ramping up and down between the two limits is illustrated in Figure 3. When the current through the inductor exceeds the upper hysteresis limit a negative voltage is applied by the inverter to the inductor. This causes the current in the inductor to decrease. Once the current reaches the lower hysteresis limit a positive voltage is applied by the inverter to the inductor and this causes the current to increase and the cycle repeats.

The bandwidth of the hysteresis current controller is given by [10],

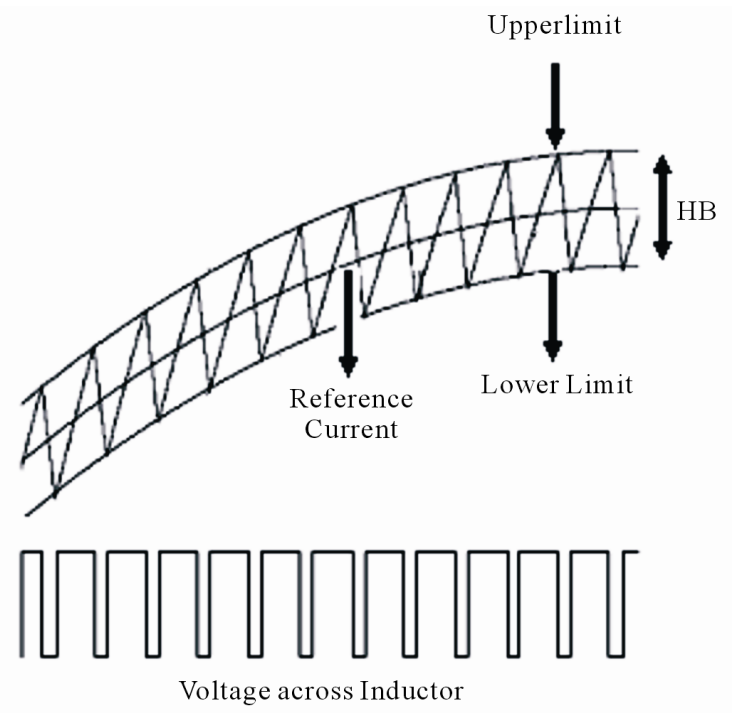

Figure 3. Waveform of hysteresis current control operation waveform.

$$
H B_{j}=\frac{V_{d c}}{6 f_{m} L_{f}}\left(1-\frac{9 L_{f}^{2}}{V_{d c}} \frac{v_{s}(t)}{L_{f}}+\frac{\mathrm{d} i_{f a}^{*}}{\mathrm{~d} t}\right), j=1,2,3
$$

where $f_{m}$ is the modulation frequency, $i_{f a}^{*}$ is the source reference current, $\frac{\mathrm{d} i_{f a}^{*}}{\mathrm{~d} t}$ represents its slope, $L_{f}$ is the decoupling inductance of the active power filter, $V_{d c}$ is the DC bus voltage and $v_{s}(t)$ is the supply voltage.

The fixed hysteresis band method explained has the drawbacks of variable switching frequency, heavy interference between the phases in case of three phase active filter with isolated neutral and irregularity of the modulation pulse position [15]. These problems result in high current ripples, acoustic noise and difficulty in designing input filter. To overcome these difficulties, this paper presents an adaptive hysteresis band current control technique in which the hysteresis bandwidth is determined by the fuzzy logic controller.

Fuzzy control is based on the principles of fuzzy logic [18]. It is a non-linear control method, which attempts to apply the expert knowledge of an experienced user to the design of a controller. Fuzzy modeling provides the ability to linguistically specify approximate relationships between the input and desired output. The relationships are represented by a set of fuzzy If-then rules in which the antecedent is an approximate representation of the state of the system and the consequent provides a range of potential responses.

In this work, the fuzzy logic controller is used to determine the hysteresis band width according to the supply voltage and the rate of change of filter current.

From Equation (7), it is noted that the hysteresis bandwidth is a function of $\frac{\mathrm{d} i_{f a}^{*}}{\mathrm{~d} t}$ and $v_{s}(t)$. Hence, these variables are taken as input to the fuzzy controller, and the hysteresis band width (HB) is the output. Five linguistic variables namely, NL (Negative Large), NM (Negative 
Medium), EZ (Zero), PM (Positive Medium) and PL (Positive Large) are assigned to the input and five linguistic variables, namely PVL (Positive Very Low), PL (Positive Low), PB (Positive Big) and PVB (Positive Very Big) are assigned to output variables. The membership functions of the input and output variables are shown in Figure 4. The fuzzy rule base with 25 rules is given in Table 1.

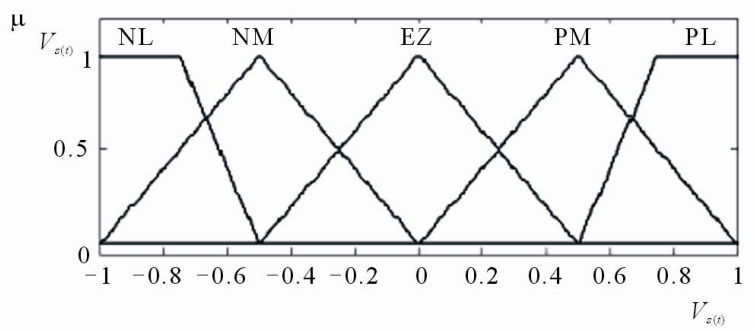

(a)

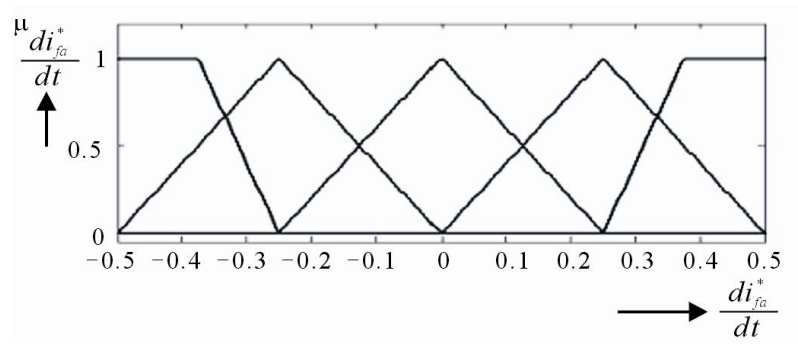

(b)

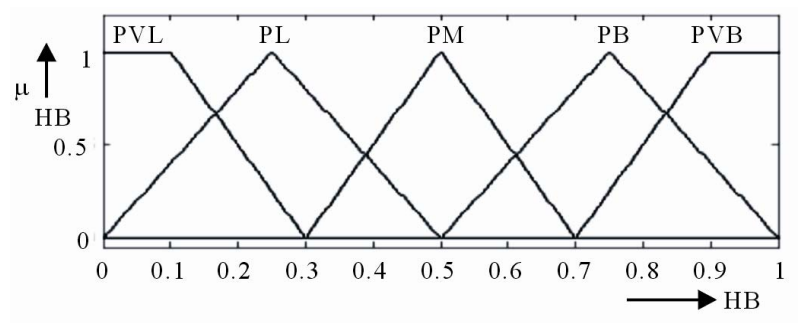

(c)

Figure 4. Membership functions for the input variables (a) $v_{s}(t)$, (b) $\frac{\mathrm{d} i_{f a}^{*}}{\mathrm{~d} t}$ and (c)output variable $\boldsymbol{H B}$.

Table 1. Fuzzy rule base for current controller.

\begin{tabular}{|c|c|c|c|c|c|}
\hline$v_{s}(t)$ & NL & NM & EZ & $\mathbf{P M}$ & PL \\
\hline NL & $\mathrm{PB}$ & $\mathrm{PM}$ & $\mathrm{PM}$ & $\mathrm{PM}$ & PB \\
\hline NM & PB & $\mathrm{PM}$ & PL & $\mathrm{PM}$ & PB \\
\hline EZ & PVB & $\mathrm{PM}$ & PVL & $\mathrm{PM}$ & PVL \\
\hline PM & PB & $\mathrm{PM}$ & PL & $\mathrm{PM}$ & PB \\
\hline PL & $\mathrm{PB}$ & $\mathrm{PM}$ & PM & $\mathrm{PM}$ & PB \\
\hline
\end{tabular}

In this approach, the switching frequency is kept constant and the current error is appreciably reduced ensuring better stability and insensitivity to parameter variation.

\section{Fuzzy-Logic Based DC Voltage Control}

The DC side of the inverter is connected to a capacitor. The capacitor provides a constant DC voltage and the real power necessary to compensate the losses of the system. In the steady state, the real power supplied by the source should be equal to the real power demand of the load plus a small power to compensate the losses in the active filter. Hence, it is necessary to maintain the DC capacitor voltage at a reference value. In this work a fuzzy logic controller is developed to maintain the constant voltage across the capacitor.

The capacitor voltage deviation and its derivative are taken as the inputs of the FLC and the real power (Preg) requirement for voltage regulation is taken as the output. Both input and output variables are represented by seven linguistic variables, namely, NL (Negative Large), NM (Negative Medium), NS ( Negative Small), ZE (Zero), PS (Positive Small), PM (Positive Medium) and PL ( Positive large). Figure 5 shows the membership functions of the input and output variables. The fuzzy if-then rules formed for controlling the $\mathrm{DC}$ voltage are given in Table 2.

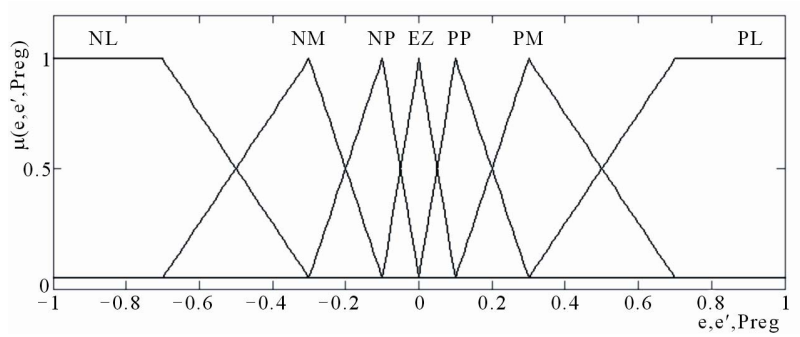

Figure 5. Membership function for the input and output variable.

Table 2. Fuzzy rule base for voltage control.

\begin{tabular}{|c|c|c|c|c|c|c|c|}
\hline de & NL & NM & NS & ZE & PS & $\mathbf{P M}$ & PL \\
\hline NL & NL & NL & $\mathrm{NL}$ & NL & $\mathrm{NM}$ & NS & ZE \\
\hline NM & NL & NL & $\mathrm{NL}$ & NM & NS & $\mathrm{ZE}$ & PS \\
\hline NS & NL & $\mathrm{NL}$ & NM & NS & ZE & PS & PM \\
\hline $\mathbf{Z E}$ & NL & $\mathrm{NM}$ & NS & ZE & PS & PM & PL \\
\hline PS & $\mathrm{NM}$ & NS & $\mathrm{ZE}$ & PS & $\mathrm{PM}$ & PL & PL \\
\hline PM & NS & $\mathrm{ZE}$ & PS & $\mathrm{PM}$ & PL & PL & PL \\
\hline PL & NL & $\mathrm{NM}$ & NS & $\mathrm{ZE}$ & PS & PM & PL \\
\hline
\end{tabular}




\section{Simulation Results}

This section presents the details of the simulation carried out to demonstrate the effectiveness of the proposed control strategy for the active filter for harmonic current filtering, reactive power compensation, load current balancing and neutral current elimination. Figure 6 shows the test system used to carry out the analysis. The test system consists of a three phase supply connected to a set of non-linear loads namely, a three-phase uncontrolled rectifier with RL load and two single-phase uncontrolled rectifiers with RLC load. The active filter is connected to the test system through an inductor L. The values of the circuit elements used in the simulation are given in Appendix A. MATLAB/SIMULINK is used to simulate the test system and the proposed shunt active filter. The simulation was conducted under three different conditions, namely, ideal source voltage, unbalanced source voltage and unbalanced-distorted source conditions. The comprehensive simulation results are presented below.

\section{Case A: Ideal Source Voltage}

First the system is simulated with ideal source voltage and without any filter. The three phase source current waveform in this case is shown in Figure 7(a). Figure 7(b) shows neutral current waveform. The Total har- monic Distortion (THD) of the distorted three-phase line currents $\left(I_{a}, I_{b} \& I_{c}\right)$ are $18.74 \%, 25.74 \%$ and $50.42 \%$ respectively. The THD level of neutral current is $87.29 \%$. The harmonic spectrum of phase and neutral currents are shown in Figure 7(c).

Next, the active filter is simulated using the proposed control strategy and connected in parallel with the load. Figure 8 shows the waveforms obtained in this case. The THD of current in phase A, B and C has reduced to $2.72 \%, 3.66 \%$ and $3.64 \%$ respectively. As shown in Figures 8(b) and (d) after the installation of the filter, the three phase source current is balanced and sinusoidal and it is in phase with the supply voltage. The harmonic spectrum of the source current is shown in Figure 8(c). As shown in Figure 9(a), the neutral current has been completely eliminated. The instantaneous real and reactive power supplied from the source in phase A is shown in Figure 9(b). From the figure it is found, that the source delivers constant real power and zero reactive power to the load which indicates that the source side power factor is maintained at unity. Figure 9(c) shows the constant voltage $(1500 \mathrm{~V})$ maintained by the fuzzy logic controller across the capacitor.

\section{Case B: Unbalanced Source Voltage}

In this case, the source voltage is made unbalanced from $0.4 \mathrm{sec}$ to $0.5 \mathrm{sec}$ as shown in Figure 10(a). The

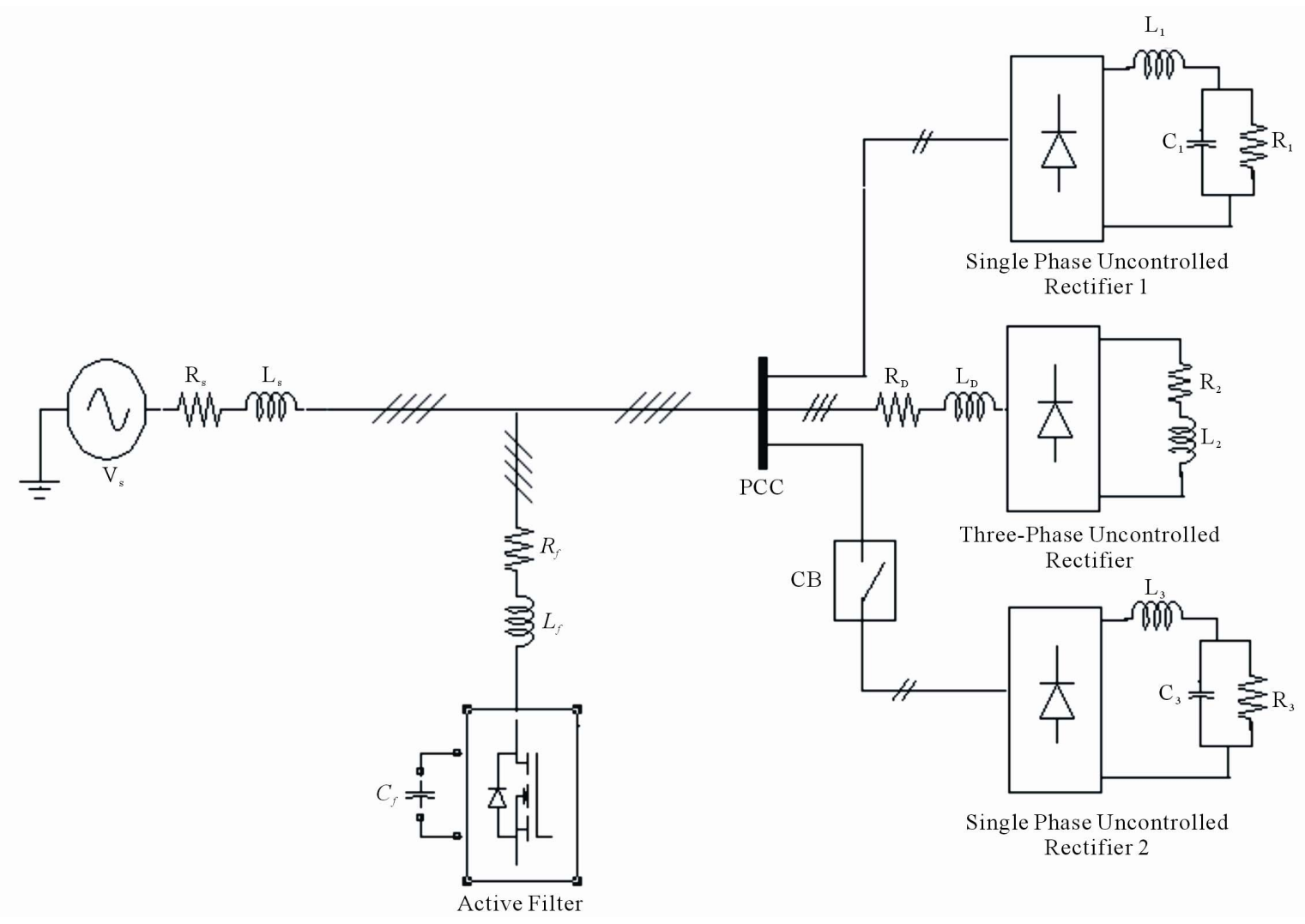

Figure 6. Test system. 


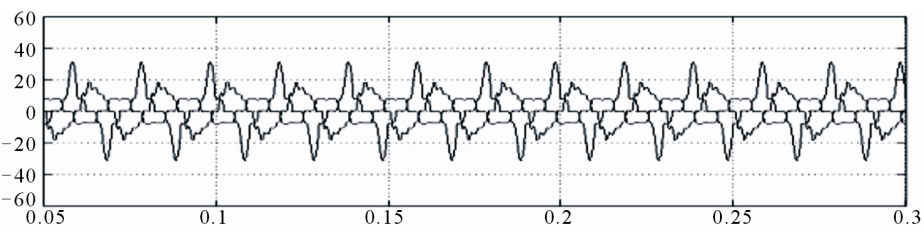

(a)

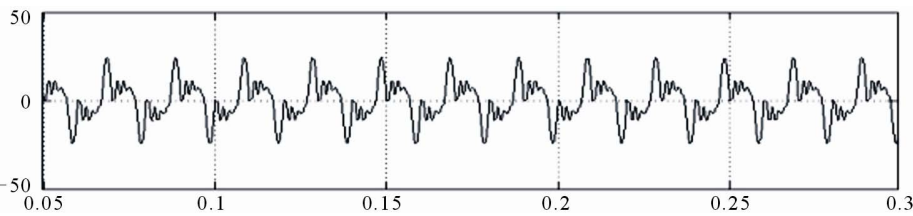

(b)
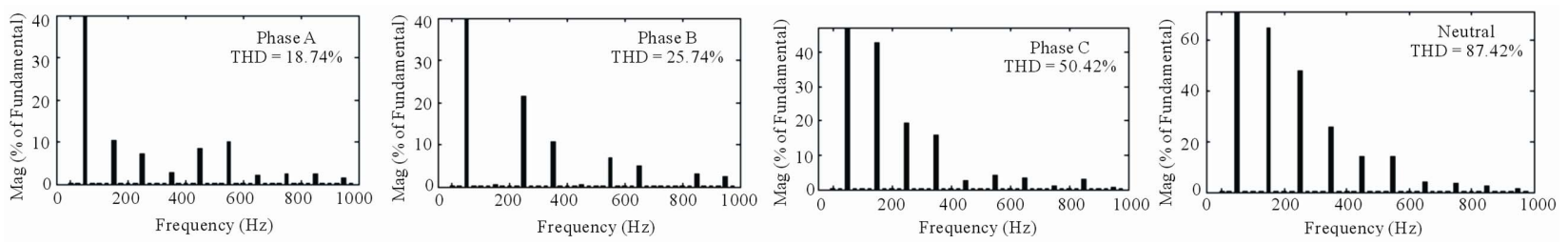

(c)

Figure 7. Distorted Phase and Neutral current and harmonic spectrum. (a) Distorted three phase source current; (b) Nautral current; (c) Harmonic spectrum of phase and netural current.

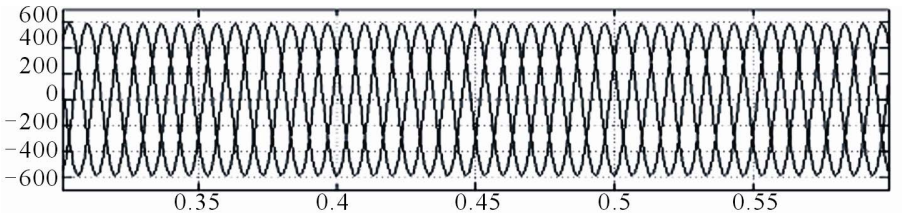

(a)

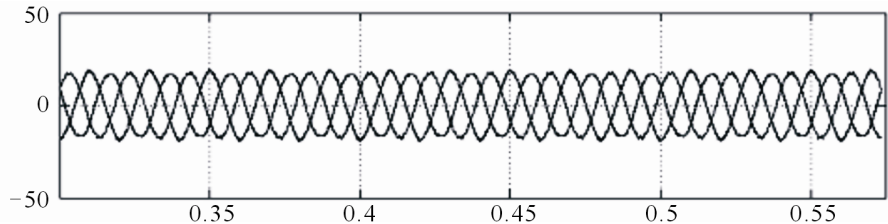

(b)
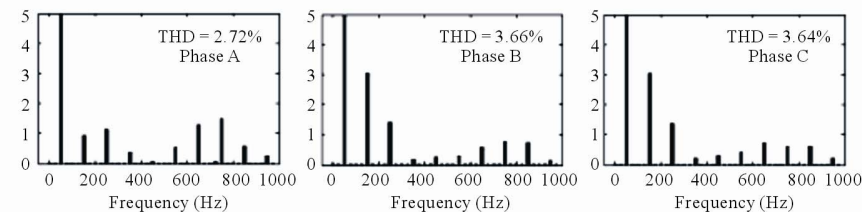

(c)

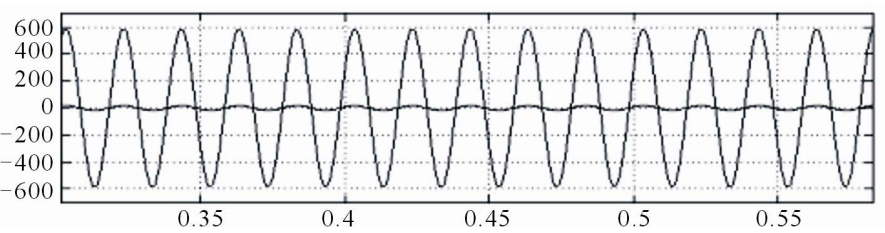

(d)

Figure 8. Harmonic current filtering under ideal supply voltage conditions with fuzzy-adaptive HBCC technique. (a) Source voltage; (b) Source current; (c) Harmonic spectrum of source current; (d) Source voltage and source current. 


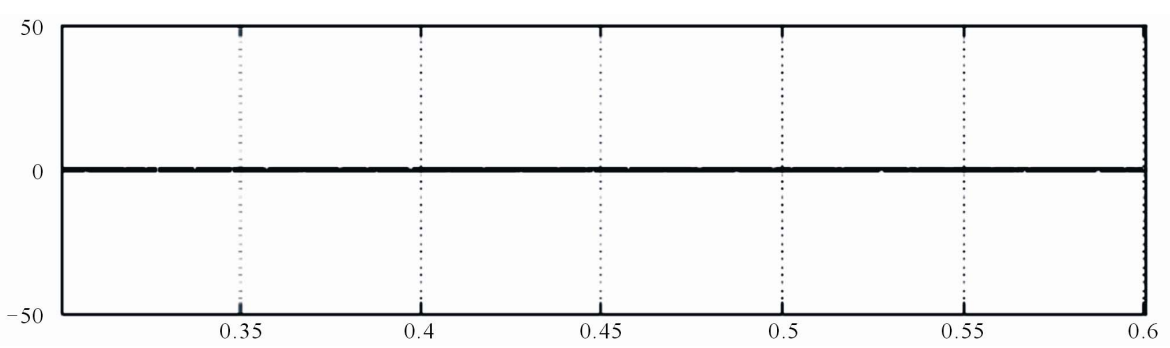

(a)

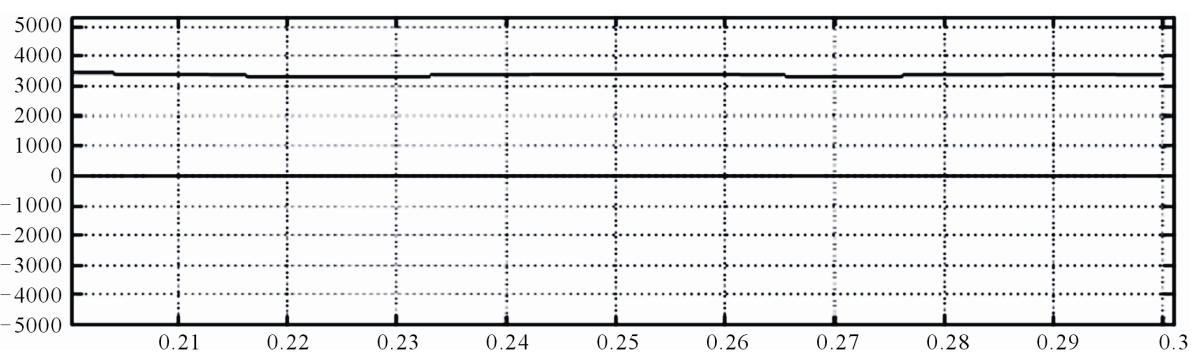

(b)

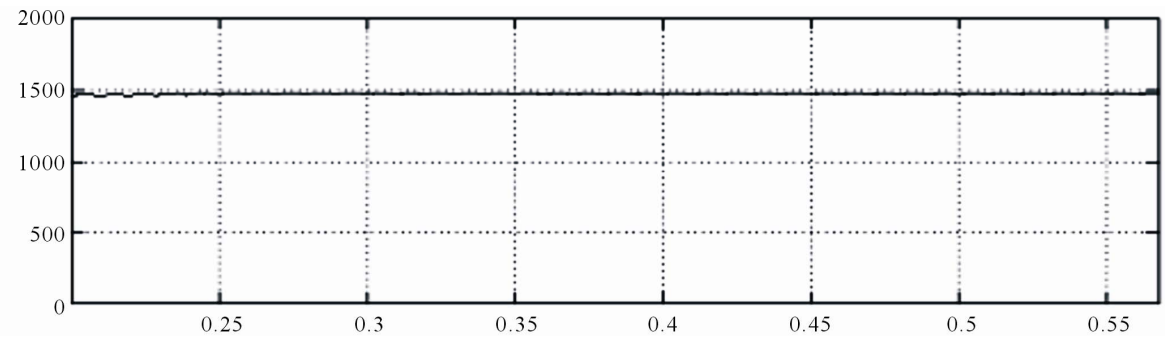

(c)

Figure 9. Reactive and neutral current compensation under ideal supply voltage conditions with fuzzy-adaptive HBCC technique. (a) Nautral current; (b) Instantaneous real and reactive power; (c) Voltage across the capacitor.

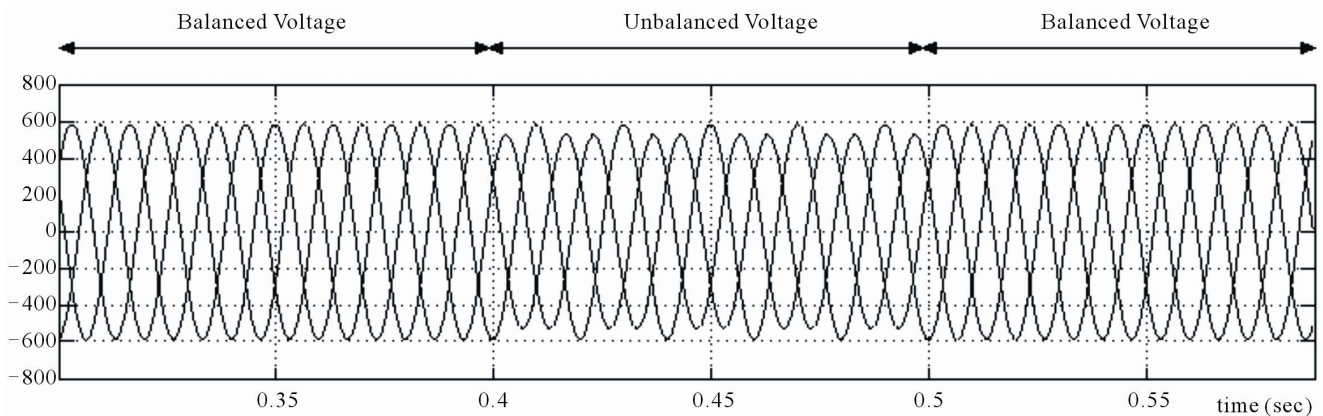

(a)

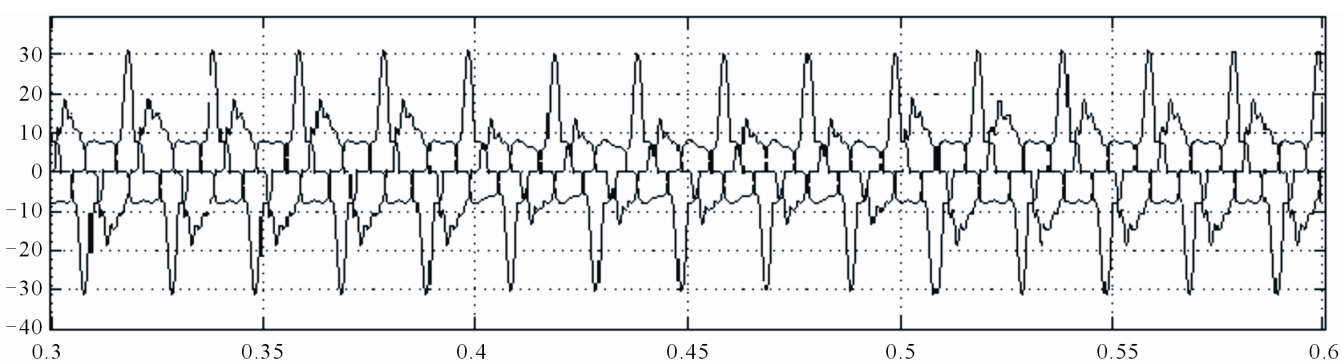

(b)

Figure 10. Unbalanced source voltage and load current. (a) Unbalanced source voltage; (b) Unbalance load current. 
unbalance is due to the voltage deviation in phase A. The unbalanced load current is shown in Figure 10(b). In the absence of the active filter, the THD level of the three phase currents and neutral current between the time period $0.4 \mathrm{sec}$ to $0.5 \mathrm{sec}$ are $20.91 \%, 25.74 \%, 50.92 \%$ and $92.06 \%$ respectively. The source current waveform and its harmonic spectrum after installing the active filter with modified $\mathrm{p}-\mathrm{q}$ theory and the proposed control strategy are given in Figure 11. In this case, the THD level has reduced to $2.9 \%, 3.7 \%$ and $3.66 \%$ in phase $\mathrm{A}, \mathrm{B}$ and
$\mathrm{C}$ respectively. For comparison, the filter was simulated with general $p-q$ theory for reference current calculation and the compensated current is shown in Figure 12. Since the compensation current references have negative-sequence component, the three phase compensated source current is not sinusoidal with general $p$-q theory. Also in this case, the THD value of source current after compensation exceeds the IEEE standard limit as shown in Table 3. This shows that the general p-q theory is not suitable for compensation under unbalanced source

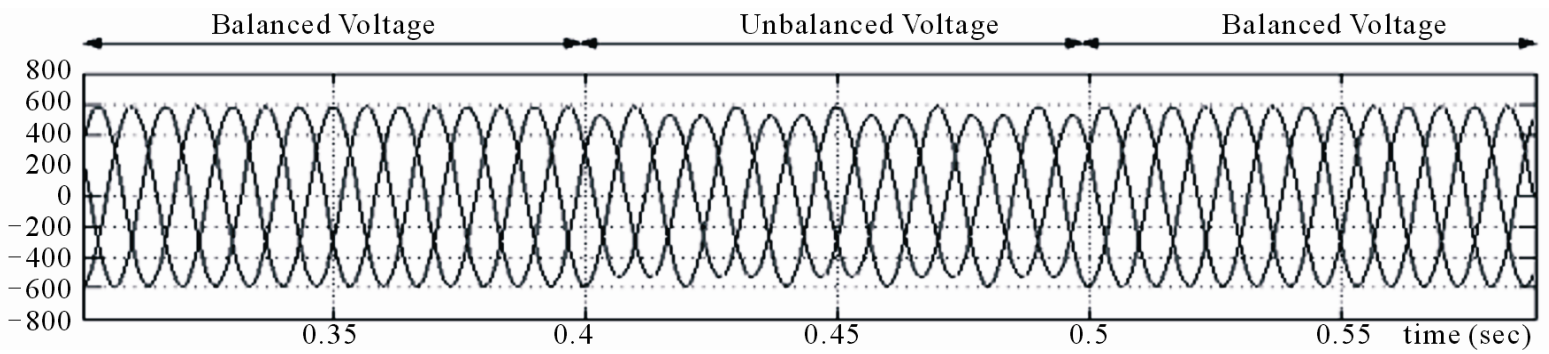

(a)

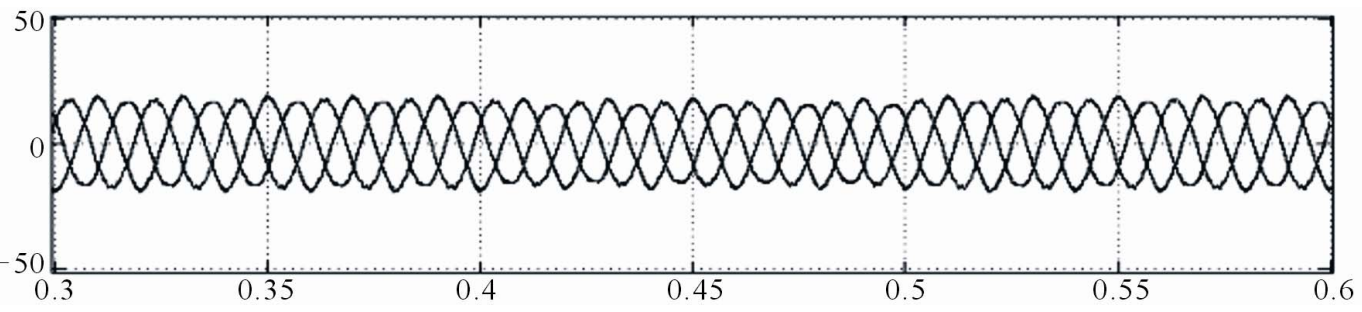

(b)
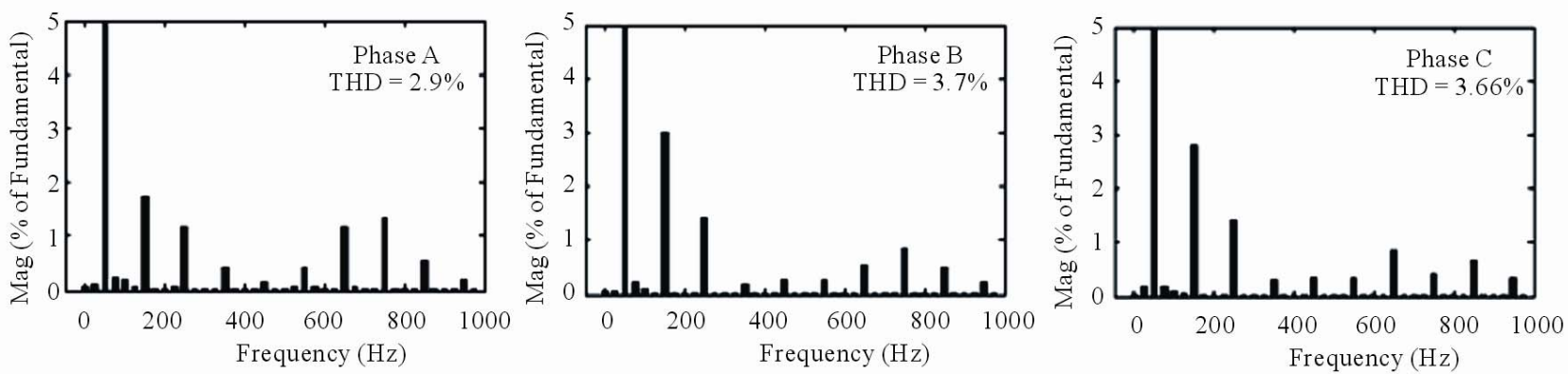

(c)

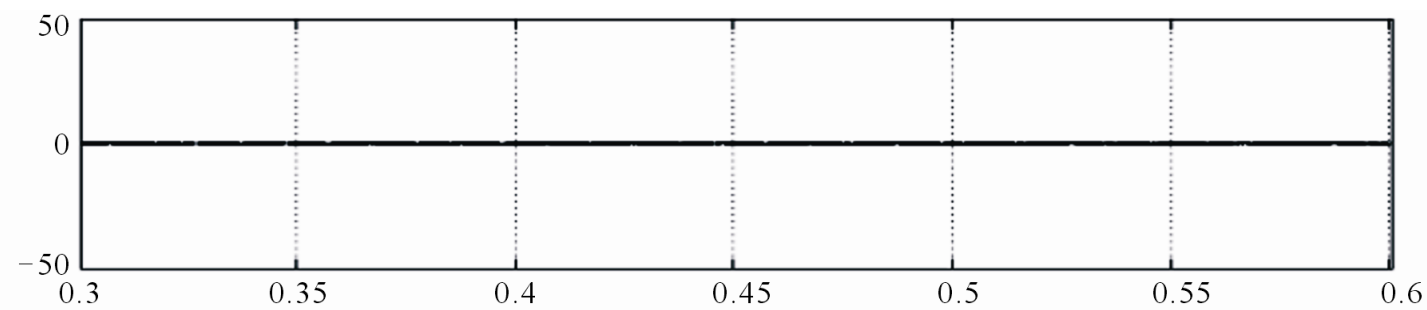

(d)

Figure 11. Harmonic current filtering under unbalanced supply voltage conditions with fuzzy-adaptive hbcc technique. (a) Unbalanced source voltage; (b) Source current; (c) Harmonic spectrum of source current (THD for 0.4 to 0.5 sec); (d) Neutral current. 


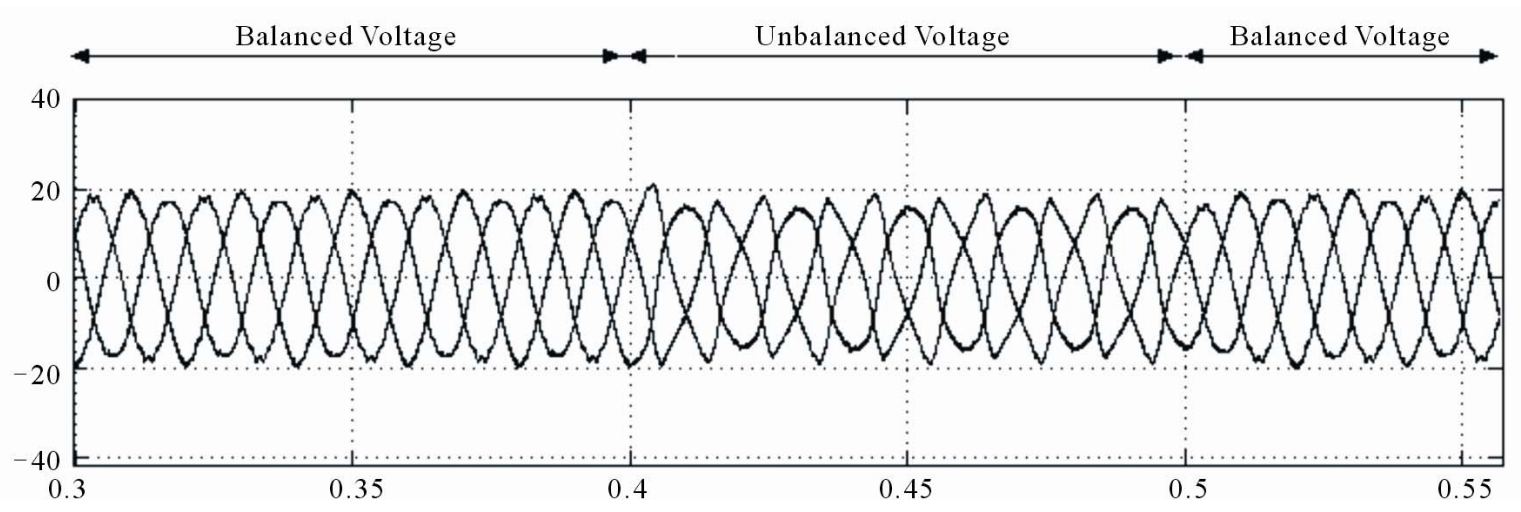

(a)
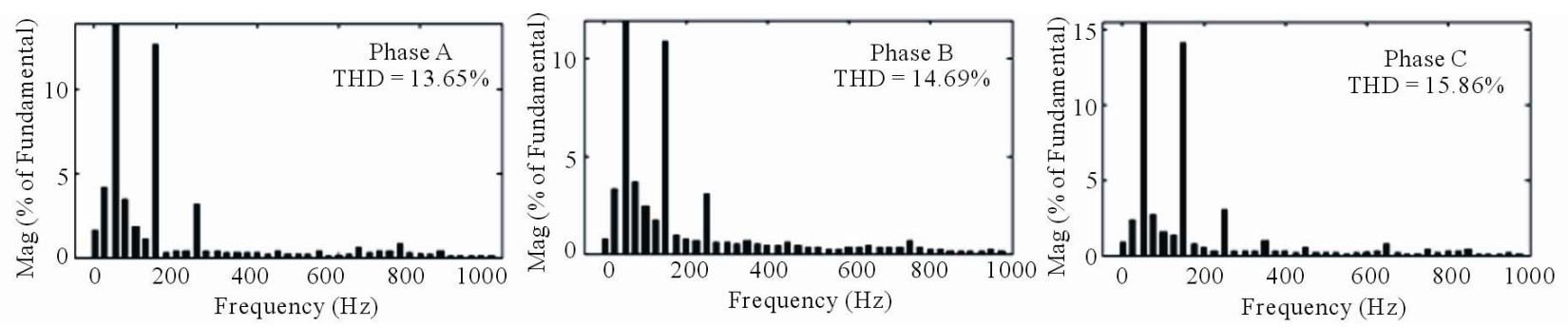

(b)

Figure 12. Harmonic current filtering using general p-q theory. (a) Load current; (b) Harmonic spectrum of load current (THD for $0.4 \mathrm{sec}$ to $0.5 \mathrm{sec}$ ).

Table 3. Detailed summary of source current and their THD under unbalanced source voltage.

\begin{tabular}{|c|c|c|c|c|c|c|}
\hline \multirow{3}{*}{ Three Phase } & \multicolumn{6}{|c|}{ Total Harmonic Distortion (THD) (\%) } \\
\hline & \multicolumn{2}{|c|}{ Without Filter } & \multicolumn{2}{|c|}{ General p-q theory } & \multicolumn{2}{|c|}{ Modified p-q theory } \\
\hline & $\begin{array}{c}\text { Balanced Voltage } \\
\quad(t>0.5 \mathrm{sec})\end{array}$ & $\begin{array}{l}\text { Unbalanced Voltage } \\
(0.4 \text { sec }<t>0.5)\end{array}$ & $\begin{array}{c}\text { Balanced Voltage } \\
\quad(t>0.5 \mathrm{sec})\end{array}$ & $\begin{array}{l}\text { Unbalanced Voltage } \\
(0.4 \mathrm{sec}<t>0.5)\end{array}$ & $\begin{array}{c}\text { Balanced Voltage } \\
\quad(t>0.5 \mathrm{sec})\end{array}$ & $\begin{array}{c}\text { Unbalanced Voltage } \\
(0.4 \text { sec }<t>0.5)\end{array}$ \\
\hline Phase A & 18.74 & 20.91 & 3.07 & 13.65 & 2.72 & 2.9 \\
\hline Phase B & 25.74 & 25.74 & 4.5 & 11.49 & 3.66 & 3.7 \\
\hline Phase C & 50.42 & 50.92 & 3.8 & 15.86 & 3.64 & 3.66 \\
\hline
\end{tabular}

voltage conditions.

\section{Case C: Unbalanced-Distorted Source Voltage}

When the three phase source voltages are unbalanced and distorted, source voltage contains negative sequence component and harmonic voltage components. The distorted and unbalanced source voltage, source current and its harmonic spectrum and neural line current before the installation of the active filter are shown in Figures 13(a)- (d). Next, the active filter is simulated with modified p-q theory for reference current calculation and with proposed control strategy and connected in parallel with the load. The simulation results are shown in Figure 14. From the figure it is evident that three phase source currents are balanced and sinusoidal after the installation of the filter. Further, it is found that the source delivers constant real power and zero reactive power to the load and the source side power factor is maintained at unity. The summary of source currents and their THD level in each phase before and after filtering are given in Table 4.

For comparison, the filter was simulated with fixed HBCC technique and the source current waveform along with its harmonic spectrum is shown in Figure 15. Performance comparison of the filter with fixed hysteresis band and fuzzy adaptive control strategies is given in Table 5. From the table it is observed that the proposed current control technique performs better than the fixed hysteresis current control technique in reducing the harmonics. 


\section{Conclusions}

This paper has presented a fuzzy logic based approach for developing the active filter for three-phase four-wire distribution system. Modified p-q theory was employed for effectively computing the reference current under non-ideal source voltage conditions. The active filter was simulated using MATLAB/Simulink and the performance was analyzed in a sample power system with a source and set of non-linear loads. The simulation results show that the proposed technique is effective in current harmonic filtering, reactive power compensation, neutral current elimination under unbalanced load and non-ideal source voltage conditions. Further the proposed tech-

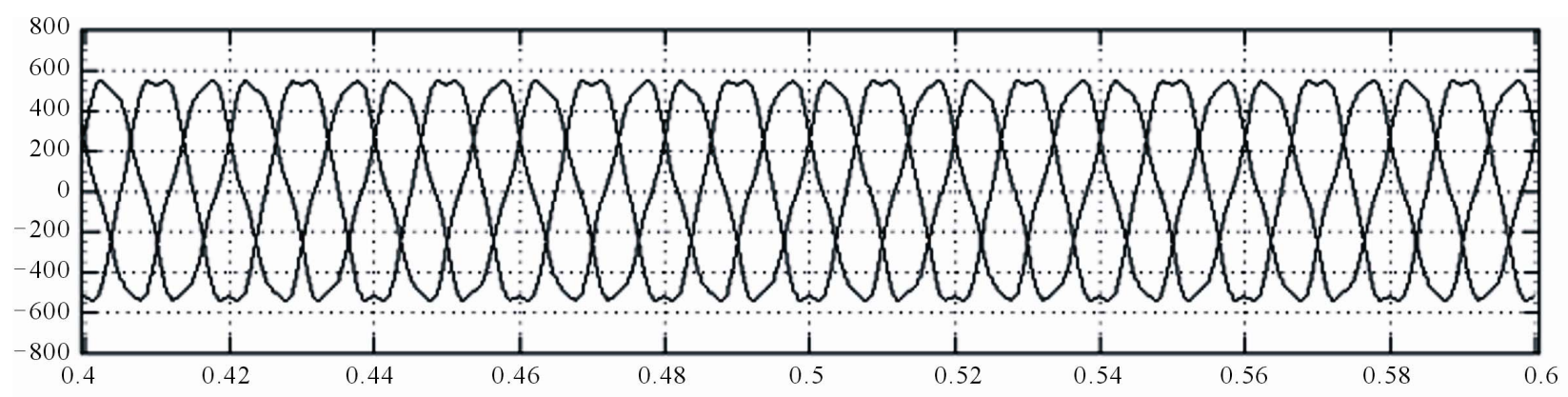

(a)

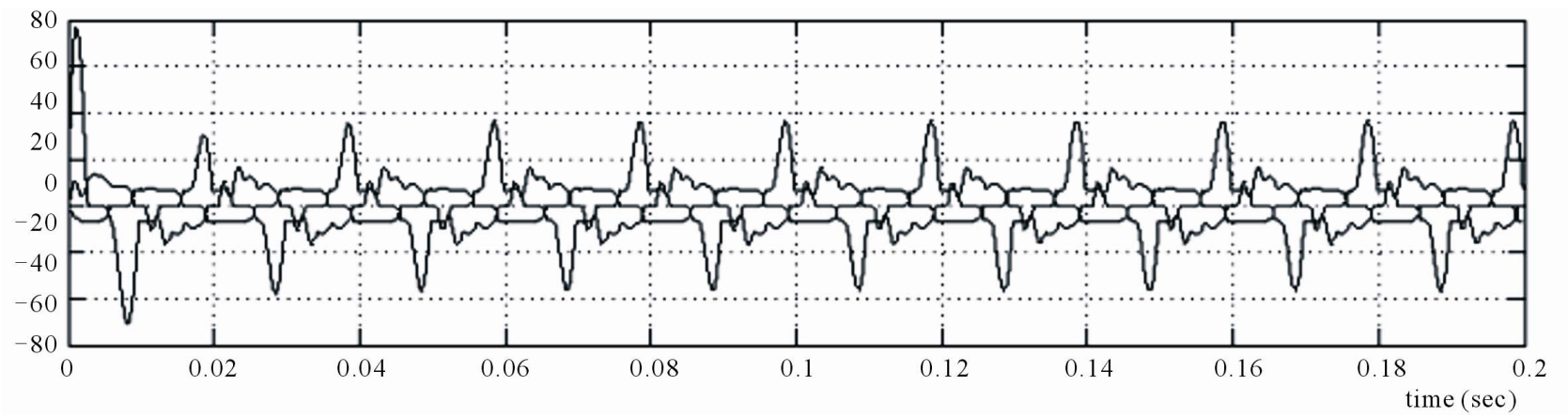

(b)

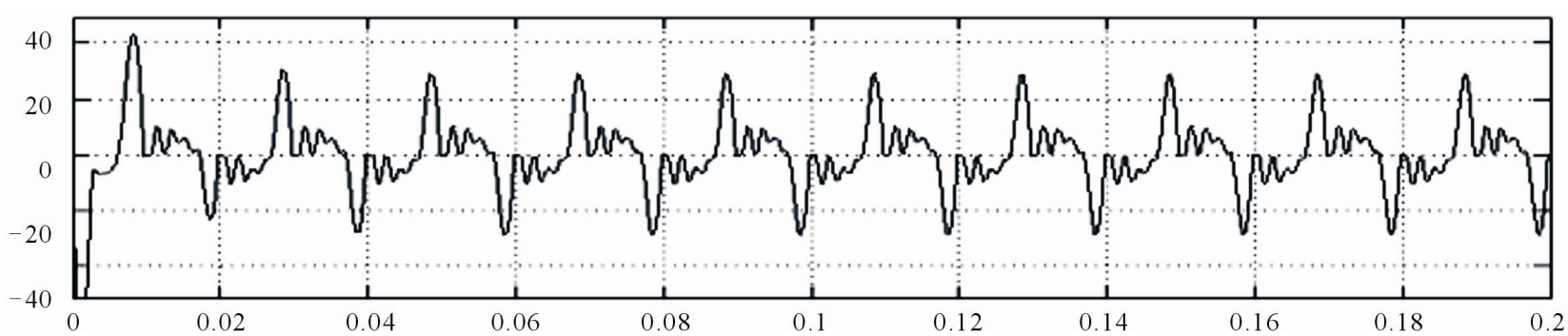

(c)
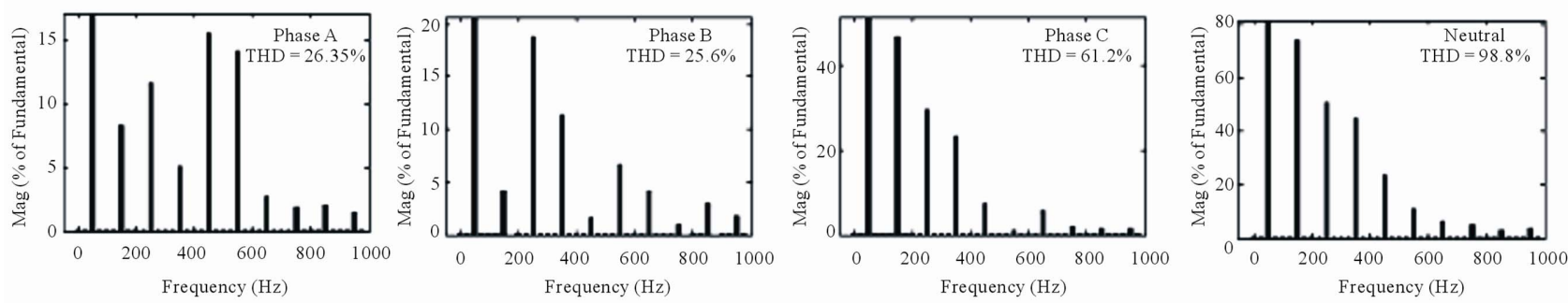

(d)

Figure 13. Waveforms under unbalanced and distorted source voltage condition. (a) Unbalanced and distorted source voltage; (b) Unbalance and distorted source voltage; (c) Neutral current; (d) Harmonic spectrum of source current. 


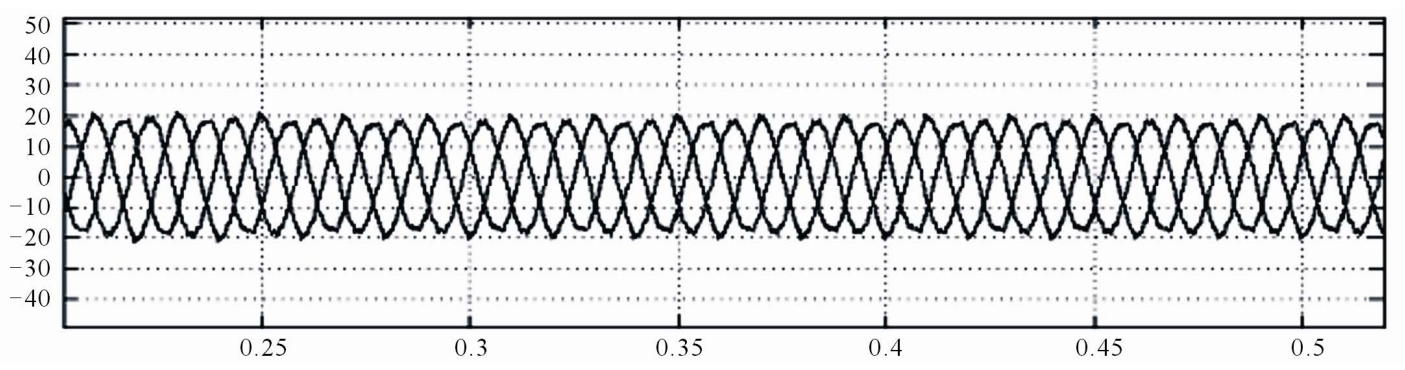

(a)
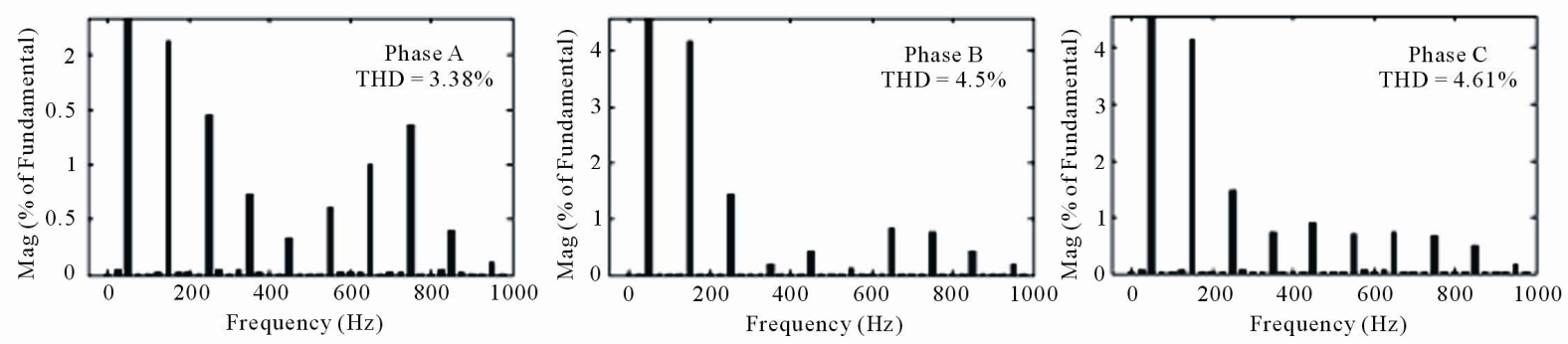

(b)

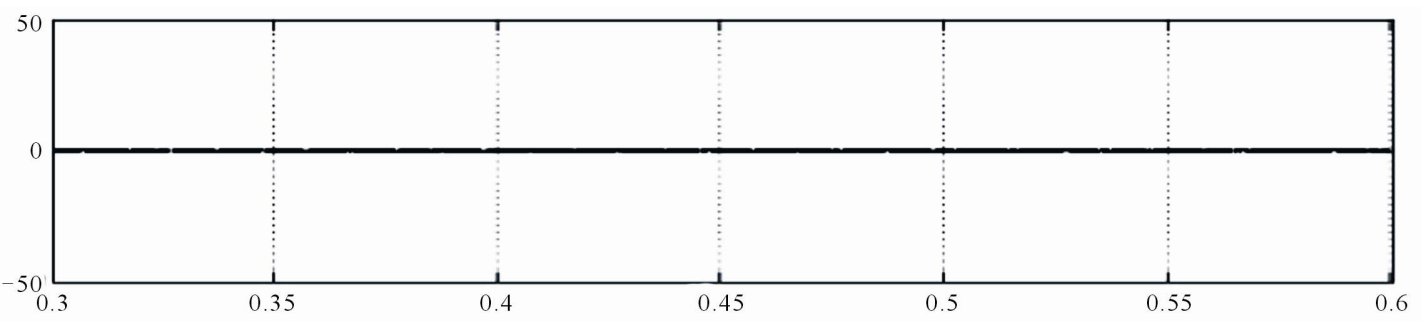

(c)

Figure 14. Harmonic current filtering under unbalanced and distorted supply voltage conditions. (a) Source current; (b) Harmonic spectrum of source current; (c) Neurral current.

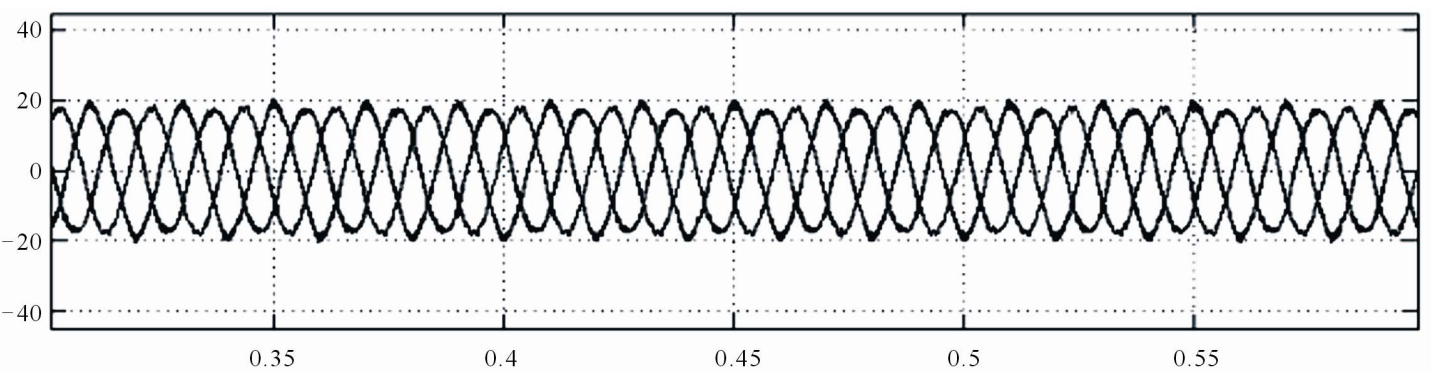

(a)
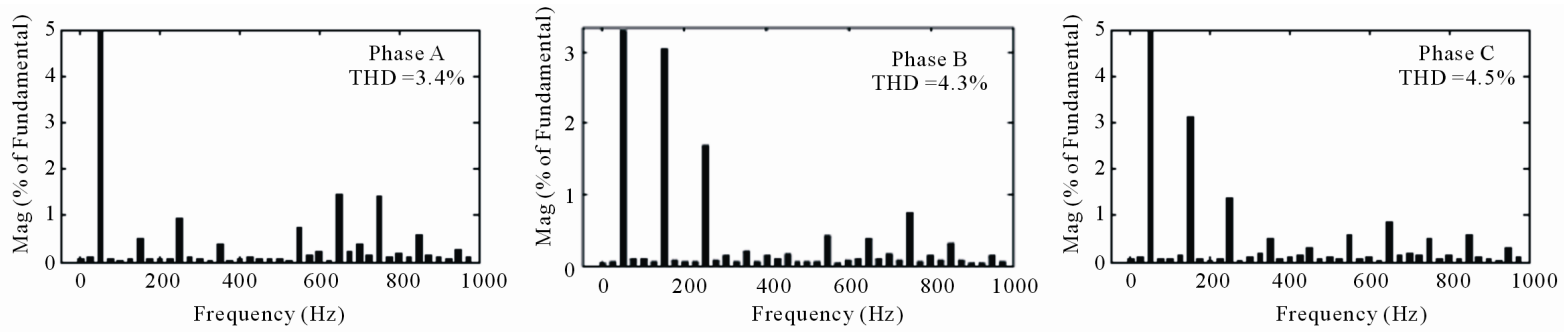

(b)

Figure 15. Harmonic current filtering under ideal supply voltage conditions with fixed HBCC technique. (a) Source current; (b) Harmonic spectrum of source current. 
Table 4. Summary of source current THD.

\begin{tabular}{ccc}
\hline \multirow{2}{*}{ Three Phases } & \multicolumn{2}{c}{ THD (\%) } \\
\cline { 2 - 3 } & Without Filter & With Filter \\
\hline Phase A & 26.35 & 3.38 \\
Phase B & 25.6 & 4.5 \\
Phase C & 61.2 & 4.6 \\
Neutral & 98.2 & - \\
\hline
\end{tabular}

Table 5. Summary of source current THD for various control strategies.

\begin{tabular}{ccccc}
\hline \multirow{2}{*}{$\begin{array}{l}\text { Voltage } \\
\text { Control }\end{array}$} & Current Control & \multicolumn{3}{c}{ THD (\%) } \\
\cline { 3 - 5 } & Phase A & Phase B & Phase C \\
\hline \multicolumn{2}{c}{ Without Filter } & 18.74 & 25.74 & 50.42 \\
Fuzzy & Fixed Hysteresis & 3.4 & 4.3 & 4.5 \\
\multirow{2}{*}{ Fuzzy } & $\begin{array}{c}\text { Fuzzy-Adaptive } \\
\text { Hysteresis }\end{array}$ & 2.72 & 3.6 & 3.6 \\
\hline
\end{tabular}

nique has quick response time and it keeps the switching frequency nearly constant with good quality of filtering.

\section{References}

[1] B. Singh, K. Al Haddad and A. Chandra, "A Review of Active Filters for Power Quality Improvement," IEEE Trans on Industrial Electronics, Vol. 46, No. 5, October 1999, pp. 960-970. doi:10.1109/41.793345

[2] L. Asiminoaei, Fr. Blaabjerg and S. Hansen, "Evaluation of Harmonic Detection Methods for Active Power Filter Applications," Applied Power Electronics Conference, Vol. 1, March 2005, pp. 635-641.

[3] K. G. Firouzjah, A. Sheikholeslami, M. R. Karami-Mollaei and F. Heydari, "A Predictive Current Control method for Shunt Active Filter with Windowing Based Wavelet Transform in Harmonic Detection," Simulation Modelling Practice and Theory, Vol. 17, No. 1, 2009, pp. 883-896. doi:10.1016/j.simpat.2009.02.008

[4] L. S Czarnecki, "On Some Misinterpretations of the Instantaneous Reactive Power p-q Theory," IEEE Transaction on Power Electronics, Vol. 19, No. 3, 2003, pp. 828-836.

[5] J. Afonso, C. Couto and J. Martins, "Ative Filters with Control Based on the p-q Theory," IEEE Industrial Electronics Society Newsletter, Vol. 47, No. 3, 2000, pp. 5-10.

[6] Z. Salam, T. P. Cheng and A. Jusoh, "Harmonics Mitigation Using Active Power Filter: A Technological Review," Elekrika, Vol. 8, No. 2, 2006, pp. 17-26.
[7] H. Akagi, E. H. Watanabe and M. Aredes, "The P-Q Theory for Active Fiter Control: Some Problems and Solutions," Revista Controle \& Automacao, Vol. 15, No. 1, 2004, pp. 945-970.

[8] H. Abaali, M. T. Lamchich and M. Raoufi, "The Three Phase Shunt Active Fiters for the Harmonics Compensation under Distorted and Unbalanced Mains Voltage Conditions," IEEE International Conference on Industrial Technology (ICIT), Vol. 1, 2004, pp. 558-563.

[9] K. G. Firouzjaz, A. Sheikholeslami, M. R. Karami and F. Heydari, "Predictive Current Control Method for Shunt Active Filter with Windowing Based Wavelet Transform in Harmonic Detection," Simulation Modelling Practice and Theory, Vol. 17, No. 1, 2009, pp. 883-896. doi:10.1016/j.simpat.2009.02.008

[10] M. S. A. Al-Haddad, F. Fnaiech and L. A. Dessaint, "Sliding Mode Control of 3-Phase 3-Wire Phase Shunt Active Filter in the dq Frame," IEEE Proceedings, Vol. 2, 2001, pp. 765-769.

[11] J. Rodriguez, J. Ponti, C. Silva, S. Kouro, A. Liendo and J. Rebolleo, "Hysteresis Current Control and DTC: An Assessment," International Journal of Electronics, Vol. 91, No. 11, 2004, pp. 639-651. doi:10.1080/00207210412331332871

[12] M. Kale and E. Ozdemir, "An Adaptive Hysteresis Band Current Controller for Shunt Active Power Filter," Electrical Power and Energy Systems, Vol. 73, No. 2, 2005, pp. 113-119.

[13] A. D. Aquila and A. Lecci, "A Current Control for Three-Phase Four Wire Shunt Active Filters," Automatika, Vol. 44, No. 3-4, 2003, pp. 129-135.

[14] L. Malesani, P. mattavelli and P. Tomasin, "High-Performance Hysteresis Modulation Technique for Active Filters," IEEE Transactions on Power Electronics, Vol. 12, No. 5, 1997, pp. 876-884. doi:10.1109/63.623006

[15] M. Kale and E. Ozdemir, "An Adaptive Hysteresis Band Current Controller for Shunt Active Power Filter," Electrical Power and Energy Systems, Vol. 73, No. 2, 2005, pp. 113-119.

[16] S. Buso, L. Malesani and P. Mattavelli, "Comparison of Current Control Techniques for Active Power Filter Applications," IEEE Transactions on Industrial Electronics, Vol. 45, No. 5, 1998, pp. 722-729. doi: $10.1109 / 41.720328$

[17] S. K. Jain, P. Agrawal and H. O. Gupta, "Fuzzy Logic Controlled Shunt Active Power Filter for Power Quality Improvement," IEE Proceedings in Electrical Power Applications, Vol. 149, No. 5, September 2002, pp. 317328.

[18] C. Sharmeela, M. R. Mohan, G. Uma and J. Baskaran, "Fuzzy Logic Controller Based Three-Phase Shunt Active Filter for Line Harmonics Reduction," Journal of Comuter Science, Vol. 3, No. 2, 2007, pp. 76-80. 


\section{Appendix A}

System Parameters

\begin{tabular}{|c|c|}
\hline Supply phase to phase voltage, frequency & $415 \mathrm{~V}(\mathrm{rms}), 50 \mathrm{~Hz}$ \\
\hline Supply line Parameters & $R_{s}=1 \Omega, L_{s}=1 \mathrm{mH}$ \\
\hline Load Parameters & $\begin{array}{l}R_{1}=50 \Omega, L_{1}=1 \mathrm{mH}, C_{1}=47 \mu \mathrm{F} \\
R_{2}=70 \Omega, L_{2}=37 \mathrm{mH} \\
R_{3}=60 \Omega, L_{3}=1 \mathrm{mH}, C_{3}=470 \mu \mathrm{F} \\
R_{D}=0.1 \Omega, L_{D}=3 \mathrm{mH}\end{array}$ \\
\hline Filter coupling Inductance & $L_{f}=3 \mathrm{mH}, R_{f}=0.5 \Omega$ \\
\hline Inverter DC bus capacitor & $1 \mathrm{mF}$ \\
\hline $\begin{array}{l}\text { DC Voltage Control: } \\
\text { Reference Voltage }\end{array}$ & $1500 \mathrm{~V}$ \\
\hline Hysteresis Band Limit & $0.5 \mathrm{~A}$ \\
\hline Sampling Time & $2 \mathrm{e}^{-6} \mathrm{sec}$ \\
\hline
\end{tabular}

